Western University Scholarship@Western

Centre for the Economic Analysis of Property Centre for the Economic Analysis of Property

Rights. Economics and Law Workshop Papers

Rights

1982

\title{
The Social Cost of Adoption Agencies
}

John P. Palmer

Follow this and additional works at: https://ir.lib.uwo.ca/economicsceapr_el_wp

Part of the Economics Commons

Citation of this paper:

Palmer, John P.. "The Social Cost of Adoption Agencies." Centre for the Economic Analysis of Property Rights. Economics and Law Workshop Papers, 82-06. London, ON: Department of Economics, University of Western Ontario (1982). 


\section{ECONOMICS AND LAW WORKSHOP}

$$
\text { 82-06 }
$$

THE SOCIAL COST OF ADOPTION AGENCIES

BY

John Palmer

Preliminary Draft

Not for Quotation or Attribution.

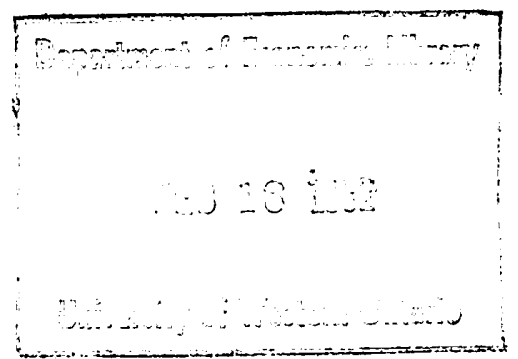

Major funding for the Centre for Economic Analysis of Property Rights has been provided by The Bureau of Corporate Affairs, Consumer and Corporate Affairs, and by the Academic Development Fund, The University of Western Ontario. The views expressed by individuals associated with the Centre do not reflect official views of the Centre, The Bureau of Corporate Affairs, or The University of Western Ontario.

Subscriptions to the Workshop papers and the Working Paper Series are $\$ 40$ per year for institutions and $\$ 25$ per year for individuals. Individual copies, if available, may be purchased for $\$ 3$ each. Address all correspondence to John Palmer, Centre for Economic Analysis of Property Rights, The University of Western Ontario, London, Ontario, CANADA N6A 5C2 
THE SOCIAL COSTS OF ADOPTION AGENCIES

by

John Palmer

Over the past few decades there has been a growing interest among economists, lawyers, and social workers in how society reallocates children from their biological parents who might be willing to give up parenthood rights to adopting parent(s) who seek to acquire parenthood rights to one or more children. ${ }^{1}$ To date, however, the discussions have been incomplete at best because they have lacked any estimates of the costs to society of using different possible reallocative schemes. While previous studies have been important in drawing attention to the issues involved and in demonstrating which items need measurement to answer the questions raised by the discussions, none has provided any of the requisite estimates.

This paper fills the numerical void which has emerged in a typically emotion-laden area by comparing some of the social costs of adoption agency placements with the costs of using a market to allocate parenthood rights. The first section discusses the lost consumer and producer surplus created by the use of non market adoption agency allocative schemes. The second section discusses some of the possible social costs which might be caused by the negative externalities which could emerge if the market were relied upon solely to allocate parenthood rights. The third and concluding section discusses qualifications to the ntmbers which emerge from the first section. 
I.

Ignoring the grey ${ }^{2}$ and black markets, it is reasonable to represent the supply function for infants as following the quantity axis at a zero price out to the quantity, $x_{A}$, which is currently being placed in adopting homes (see Figure 1). This quantity is forthcoming under current conditions even though the mothers receive no market compensation for their children, presumably because the biological mothers receive some form of non-market compensation for bearing children or, and more likely, because of accidental conception. In fact, with the relatively low cost and widespread availability of abortions, it is also difficult to argue that the current economic price (in terms of opportunity costs in the form of lost wages or foregone leisure) paid to mothers is much less than zero either.

As the price begins to rise above zero, it is unlikely that at low prices many, if any, women would perceive an incentive to conceive a child for the marketplace. Nevertheless, the price elasticity of supply is perhaps somewhat greater than zero because as the price increases above zero, some of the children accidentally conceived would no longer be kept and raised by one or both of their biological parents but would instead be put up for adoption.

To move from the realm of accidental to intentional conception for the marketplace would require a price considerably above zero and would also substantially alter the price elasticity of supply. Assuming that the expected opportunity costs to most mothers in this market might be approximately $\$ 2000$ during the last month or so of pregnancy and after the birth of the child, it seems reasonable to construct the supply curve so that it eventually becomes horizontal at this price (net of legal and medical expenses). This supply 
Figine 1

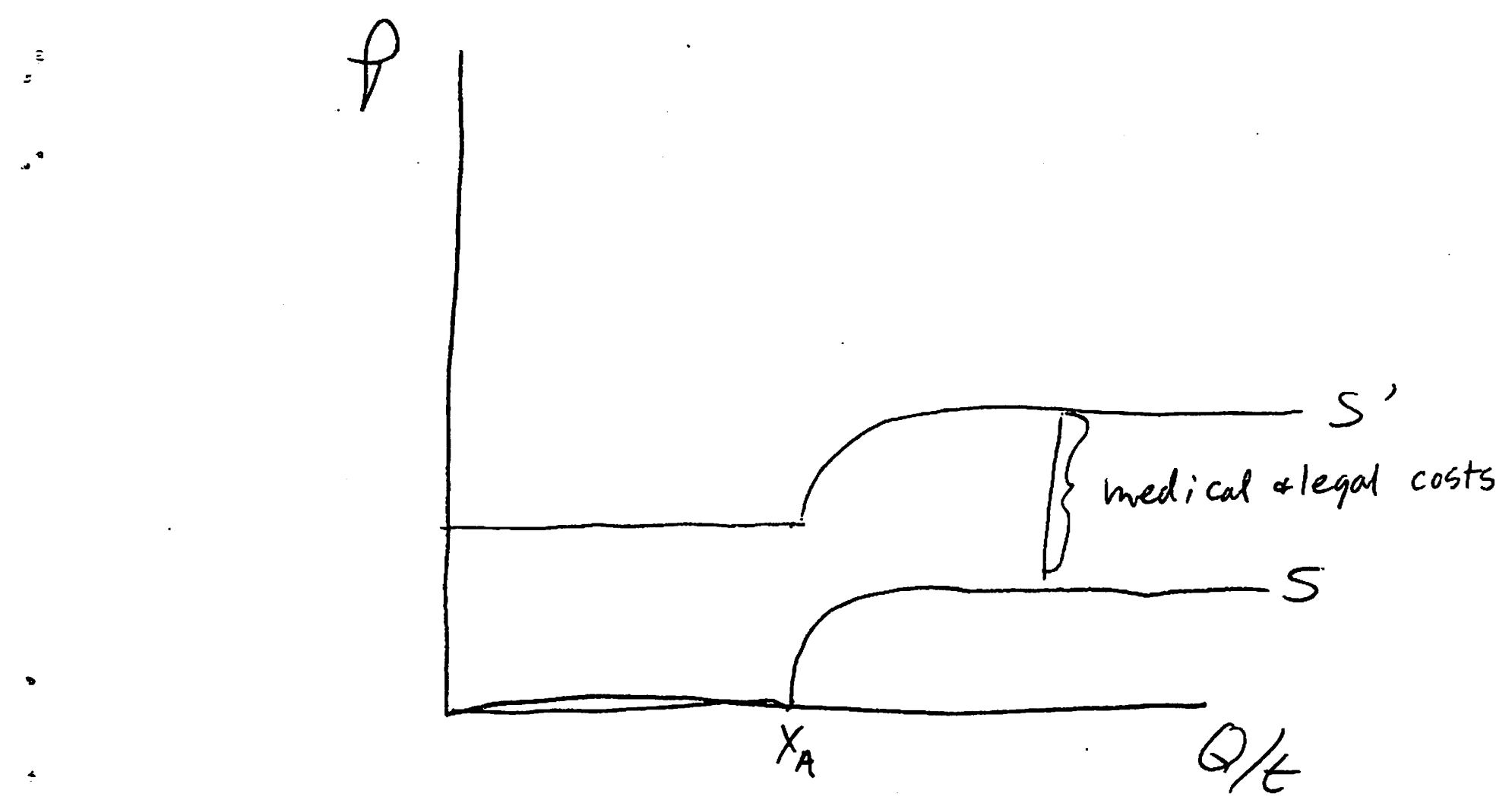




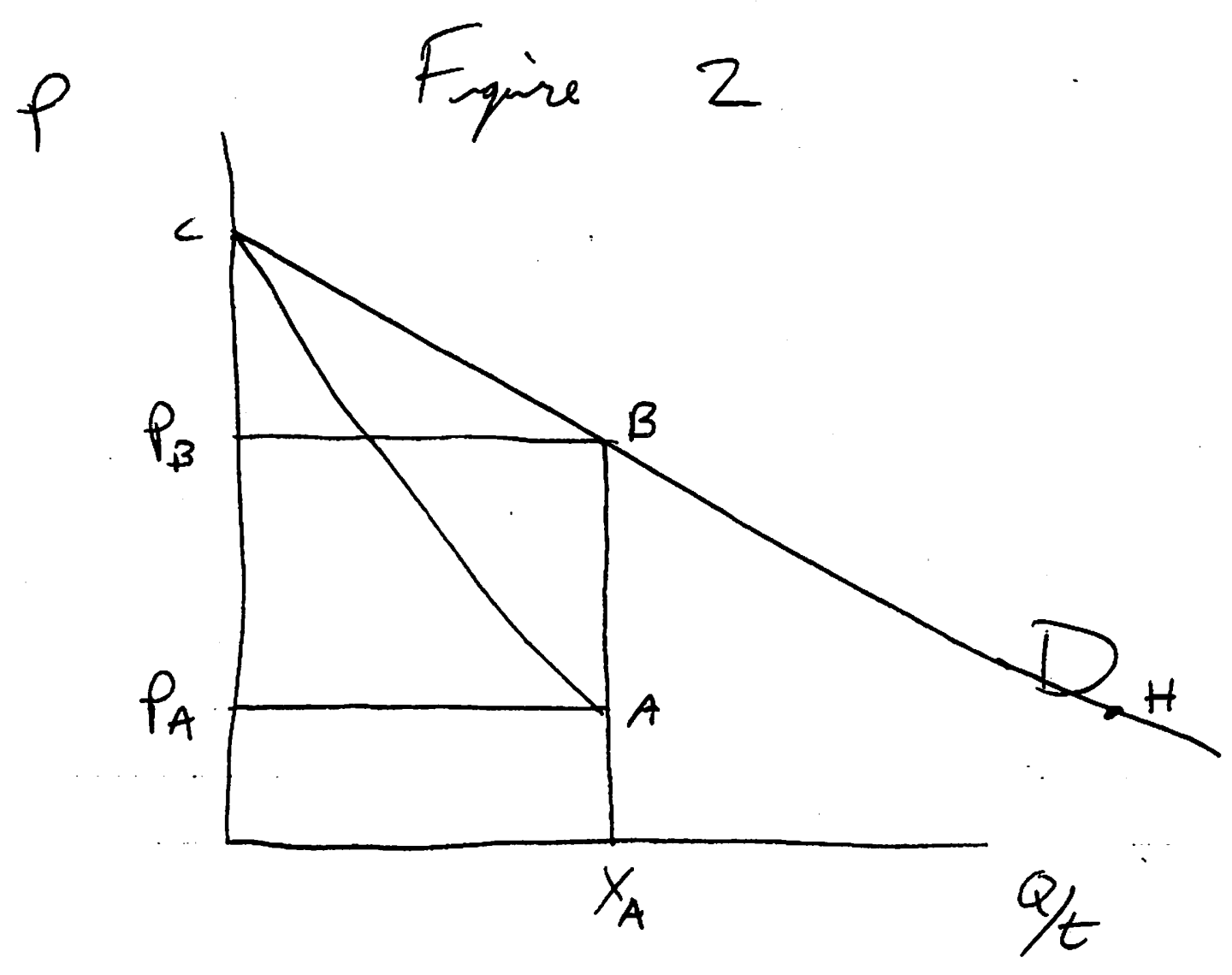


curve is shown in Figure 1 along with a similar one which is higher by a fixed amount to represent medical and legal costs.

The demand for adoptable infants is represented by a linear demand curve in Figure 2. The lost consumer and producer surplus resulting from the use of adoption agencies rather than the market can be thought of as emanating from two different sources. First, the agencies allocate some of the available $x_{A}$ quantity of children to parents who would be willing and able to pay more than $\mathrm{P}_{\mathrm{A}}$, the price charged by the agencies to cover medical and legal expenses, but less than $\mathrm{P}_{B}$, the price that would just clear the demand side of the market for that quantity of children. This allocation creates a net loss of consumer surplus, the amount of which depends on how closely the agencies' placements allign with allocations that would occur in the marketplace. If the agency allocations were completely random, they would be spread evenly along the demand curve between points $C$ and $H$. The consumer surplus generated from the random allocation of $\mathrm{X}_{\mathrm{A}}$ children can be represented as the straight 1 ine $\mathrm{C}_{\mathrm{A}}$ in Figure 2, 1ying below the demand curve. Triangle ABC represents the lost consumer surplus. To the extent that agencies are more likely to allocate children to parents willing to pay higher prices, the allocations would lie along a curved 1 ine between points $\mathrm{C}$ and $\mathrm{A}$ in Figure 3. Such a possibility seems quite reasonable, for one would expect that parents willing but banned by law from purchasing an infant would be more likely to devote resources to influencing the decisions of the agency, e.g., by reading more about what factors influence agency decisions, attending meetings, doing volunteer work with children, and acquiring material possessions designed to impress 
Fiques

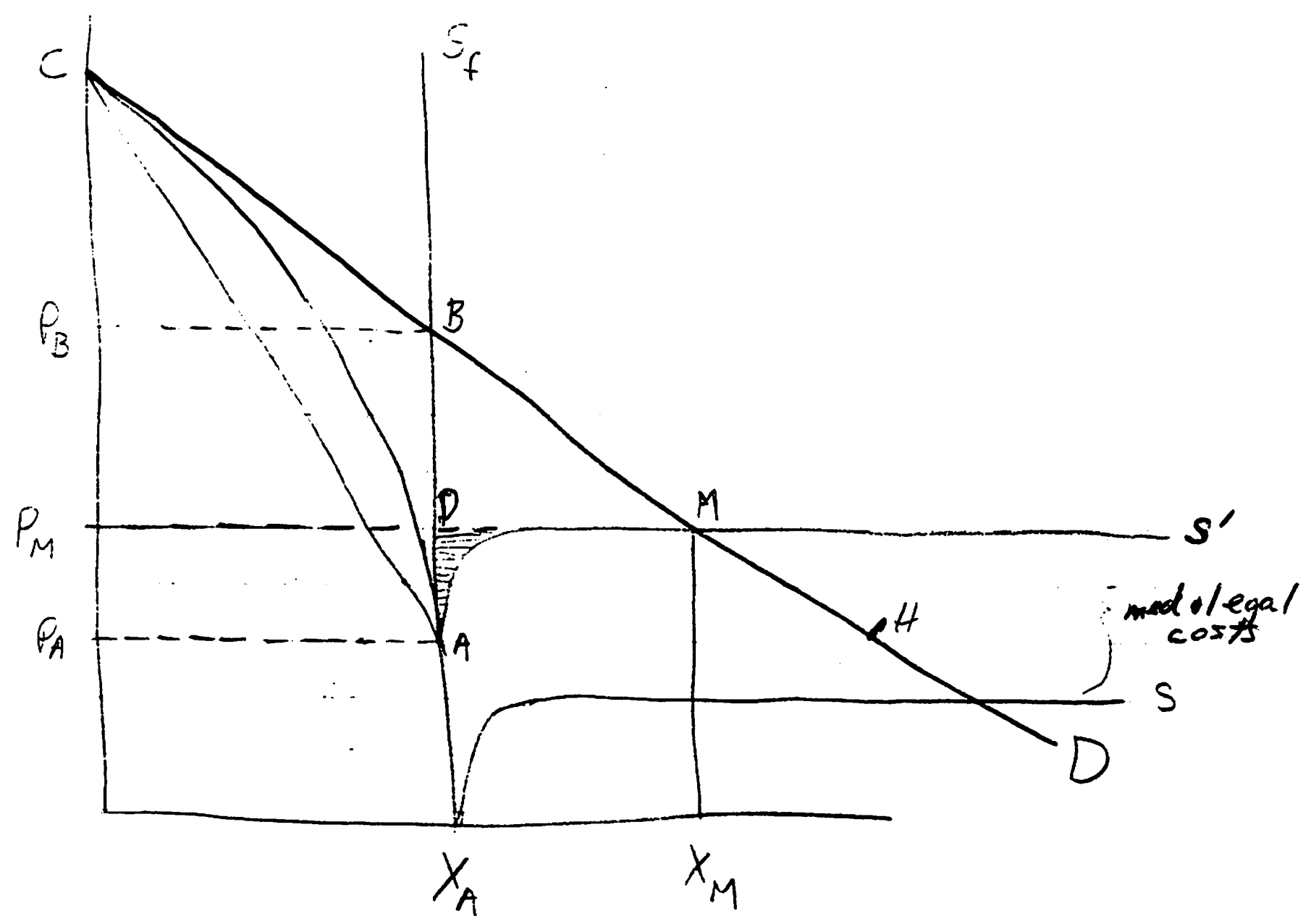


agencies favourably. Perhaps, too, the mere relative intensity of their desire would influence social workers' decisions.

The demand curve shown in Figures 2 and 3, can be represented by the equation

$$
P=C-\frac{C-P_{B}}{X_{A}} Q \text {. }
$$

One way to represent the agency allocation of children (the bowed curve between $\mathrm{C}$ and $\mathrm{A}$ ) is

$$
P=C-\frac{C-P_{B}}{X_{A}} Q-\frac{\left(P_{B}-P_{A}\right) Q^{n}}{X_{A}^{A}}, n \geq 1,
$$

where $\mathrm{n}$ is the degree to which agency allocation Adptures potential consumer surplus. For random allocation, $n=1$, and the children are allocated along the straight line $C A$. The coefficient $n$ increases as agency allocation captures increasing amounts of potential consumer surplus, and the agency allocation curve between $\mathrm{C}$ and $\mathrm{A}$ becomes increasingly bowed outward, away from the origin. In the limit, $n$ approaches infinity as the agency allocation yields all of the potential consumer surplus, and the agency allocation curve follows the line segments CBA (Figure 4).

The lost consumer surplus from having agency vs. market allocation of $\mathrm{X}_{\mathrm{A}}$ adoptable infants (shown as the vertically shaded area in Figure 4) is the integral of equation (1) minus the integral of equation (2) evaluated between 0 and $x_{A}$, or

$$
\int_{0}^{X_{A}} \frac{P_{B}-P_{A}}{x_{A}^{n}} Q^{n} d Q=\frac{\left(P_{B}-P_{A}\right) X_{A}}{n+1} .
$$




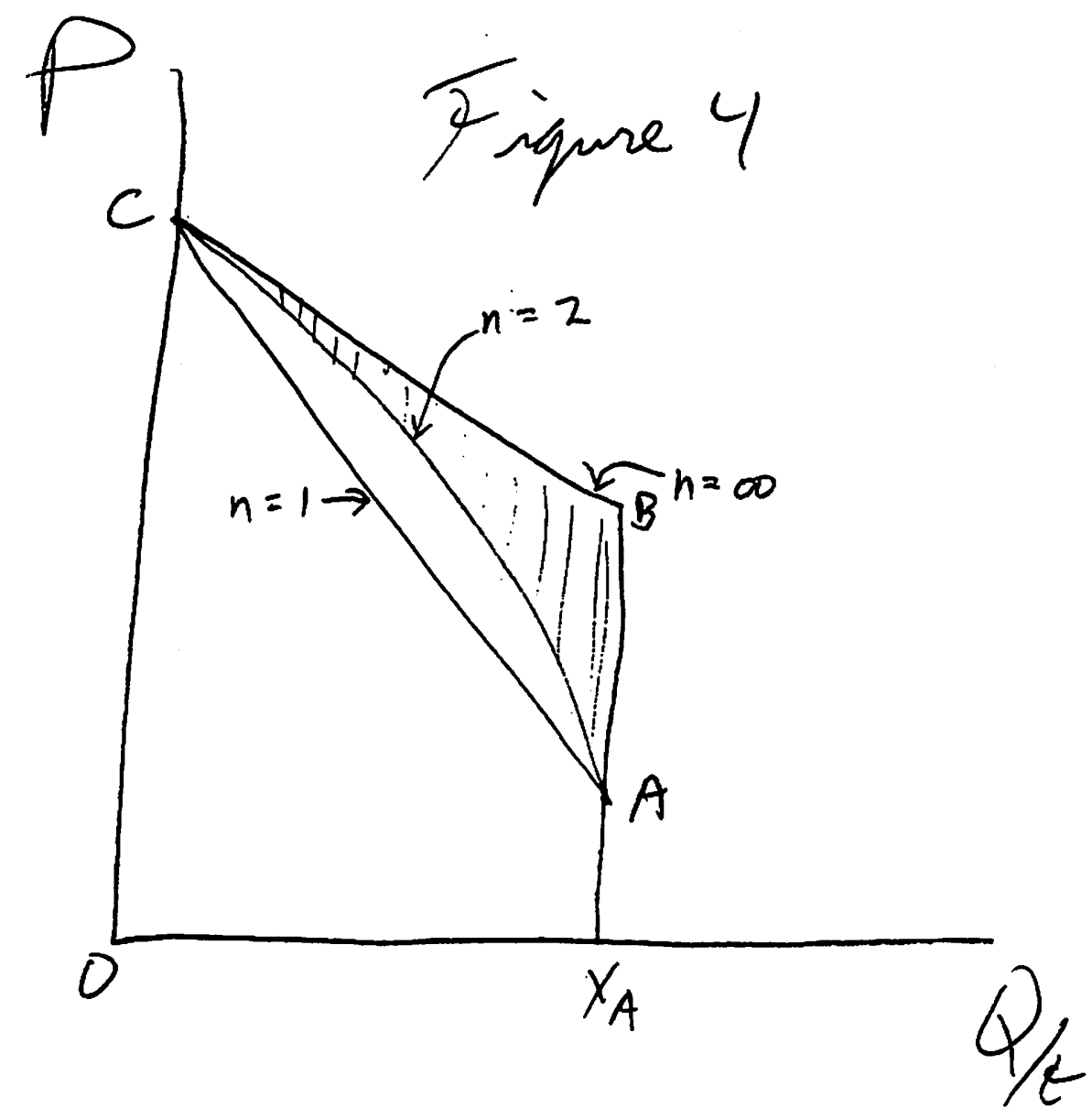


The value of expression (3) is the area between the angle $A B C$ and the curve CA. Some evidence exists indicating that $\mathrm{X}_{A}$ is approximately 100,000 , and that $P_{A}$, the current amount paid by adopting parents, is approximately $\$ 3,000$. Evidence about the market clearing price for 100,000 infants is nonexistant; however, tales abound of grey market prices of between $\$ 5,000$ and $\$ 25,000$, and of black market prices of $\$ 25,000$ or more. ${ }^{3}$ Nor is it clear what $n$ equals. Table 1 shows the values of expression (3) for $n=1,5$, and 10 and for $P_{B}=7,12$, and 23 thousand dollars.

\section{Table 1}

(in millions of dollars)

\begin{tabular}{|c|c|c|c|}
\hline & 1 & 5 & 10 \\
\hline$\$ 7,000$ & 200 & 66.7 & 36.4 \\
\hline $\begin{array}{l}12,000 \\
23,000\end{array}$ & $\begin{array}{r}450 \\
1000\end{array}$ & $\begin{array}{l}150 \\
350\end{array}$ & $\begin{array}{r}81.8 \\
190.9\end{array}$ \\
\hline
\end{tabular}

This table indicates that even if the market clearing price were fairly low and even if adoption agencies allocated children fairly closely to the demand curve, the lost consumer surplus per year would be quite large (for $n=10$ and $P_{B}=\$ 7,000$, the loss would be $\$ 36.4$ million per year). This is the loss due to the non-market allocation of $\mathrm{x}_{\mathrm{A}}$ children.

The second type of loss arises because legal restrictions on the market of children artificially reduce the number of children available for adoption. If biological mothers were paid for their right to be parents of adoptable infants, some children for whom parenthood is now retained by thier biological mothers would be available for adoption, and additional children would 
be conceived specifically for the adoption market. If the adoption agencies created as much consumer surplus as possible, i.e., the value of $n$ in expression (3) is infinite and if the value of expression (3) itself equals zero (this is an important 'if' to be elaborated upon later), the value of this second type of loss is the area ABM in Figure 3. The lost consumer surplus is DBM and the lost producer surplus is ADM. It will be assumed throughout that area ADM is negligibly small (area $P_{M} P_{A} A D$ is a transfer, not a loss). Evaluating $E$, the price elasticity of demand, at $P_{B}$ and $x_{A}$, the area of $B D M$ is

$$
\mathrm{BDM}=\frac{\left(\mathrm{P}_{\mathrm{B}}-\mathrm{P}_{\mathrm{M}}\right)^{2} \mathrm{EX_{A }}}{2 \mathrm{P}_{\mathrm{B}}} \text {. }
$$

In addition to values for $P_{B}, X_{A}$, and $P_{M}$, all discussed earlier, a value for $\mathrm{E}$ is necessary to determine area BDM. De Tray has observed that the elasticity of demand for children with respect to female wage rates is .3 using OLS and .8 using TS LS. Ashenfelter has expressed considerable doubt about the reliability of the De Tray estimates. ${ }^{4}$ Table 2 presents the values for expression (4), letting $E$ take on values of $.3, .8$, and 1.0 , and letting $P_{B}$ as before take on values of 7,12 , and 23000 dollars.

$\underline{\text { Table } 2}$

(in millions of dollars)

\begin{tabular}{|c|c|c|c|}
\hline & .3 & .8 & 1.0 \\
\hline 7000 & 8.6 & 22.9 & 28.6 \\
\hline 12000 & 61.3 & 163.3 & 204.2 \\
\hline 23000 & 211.3 & 563.5 & 704.4 \\
\hline
\end{tabular}

Even if adoption agencies maximize the generation of consumer surplus based on the number of children available to them, a welfare loss of at least 8.6 million 
dollars per year is created anyway because of legal restrictions on the sale of parenthood rights.

The total welfare loss due to adoption agencies cannot be calculated by adding selected numbers from Tables 1 and 2. The problem of external costs and error costs is discussed later in the paper. In addition, adding the two areas of Figure 1 would involve some double counting except in the extreme case of $n=\infty$ (i.e., the shaded area of Figure $4, A B C=0$ ). If area $A B C$ is positive, that means that some parents located along segment $B M$ of the demand curve are receiving children; their consumer surplus should not be included in the triangle BDM because it is not a social loss. The loss, in fact, occurs because those very people received children when others who value parenthood even more did not; and area $A B C$ is designed to measure precisely this difference. Consequently, if $A B C$ and $D B M$ are added together, an amount must be subtracted from their total to obtain an accurate measure of consumer welfare loss. The precise amount to be subtracted is the shaded "triangular" area $K$ under curve $A C$ between price $P_{B}$ and price $P_{M}$ (see Figure 5), for this is the consumer surplus accruing to some of the parents who fall between $B$ and $M$ on the demand curve. In other words, welfare loss is (4.a) $\quad L=A B C+A B M-K$

and because ADM is assumed to be equal to zero, (4.b) $\quad L^{\prime}=A B C+D B M-K$.

Area $\mathrm{K}$ is a fraction of area DBM; the size of the fraction varies inversely with $n$, which measures the curvature of AC (contrast areas $K$ and $K^{\prime}$ ), inversely with $P_{B}$, and inversely with $E$, the price elasticity of demand. For 


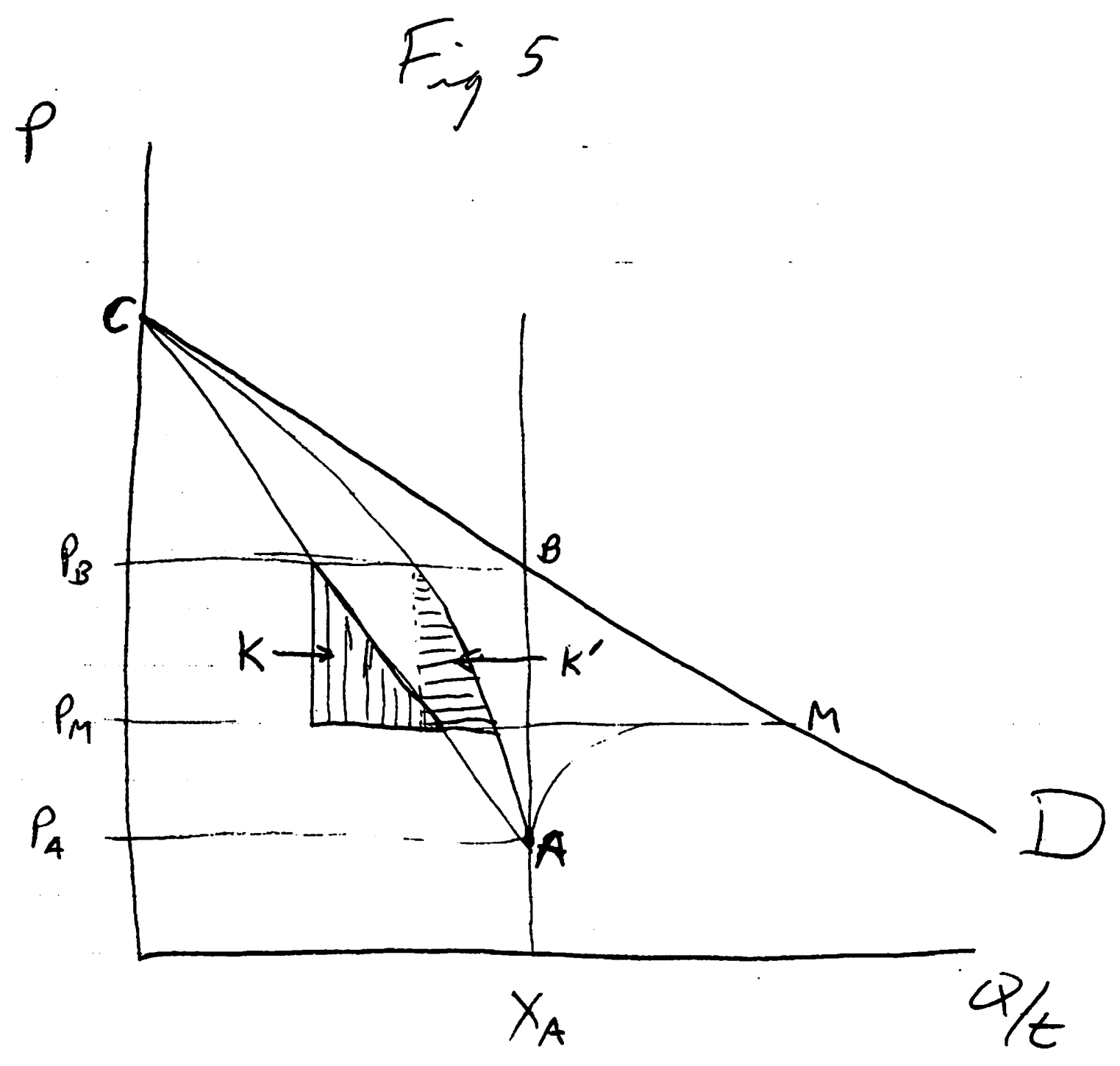


$\mathrm{n}=1, \mathrm{P}_{\mathrm{B}}=\$ 7,000$, and $\mathrm{E}=0.3$, all of which would cause relatively high values of the fraction, $K$ would equal approximately $85 \%$ of area $\mathrm{BDM}_{\bullet}{ }^{5}$ of course, when $n=1$ the welfare loss measured by area $A B C$ is so large that the effect of $\mathrm{K}$ and $\mathrm{BDM}$ is not particularly large. With this in mind, consideration of the values in Tables 1 and 2 suggests that in terms of Figures 1-5 the welfare losses caused by adoption agencies are at least $\$ 40$ million per year and could be as high as $\$ 1.5$ billion per year. II.

One oft-stated reason for eschewing the market in favour of adoption agencies to allocate parenthood rights arises from the position taken by many social workers that if children are carefully placed in adoptive homes, the reduced social costs arising from externalities such as crime and/or mental illness will more than make up for the other social costs of not using a market. It is, of course, difficult to compare the outcomes of adoptions via agencies versus the market since there is not a ready market available generating data for such a test. Nevertheless, some studies of adoption outcomes do provide some useful data which can at least provide an inkling of the comparative outcomes.

In a follow-up study of adoption, social workers interviewed the parents and children in homes in which children had been placed by adoption authorities approximately seven to fifteen years previously. Among other things, the interviewers rated the overall outcome of each adoption on a four-category scale of low, fair, good, and superior. One would expect that a majority of the adoptions would be rated good or superior for two reasons. First, it would be surprising if most family relationships, adoptive or not, were rated only low or fair. Second, in each of these situations, 
the adopting hopses were presumably interviewed and screened prior to the adoption so that many of the potential adoptions which might not have worked out very well were not proceeded with in the beginning. Of the 250 families studied, the global rating on the adoption outcome was 23 low, 72 fair, 116 good, and 39 superior.

Each placement was also retroactively assessed "ex ante" by having researchers examine"...information about the child's background, characteristics, problems, etc., and on the prospective parents' potential for enhancing his development and adjustment. ... The raters attempted to determine the appropriateness of the placements on the basis of the above considerations and on the case record data available about parents and child up to the point of legal adoption. Their ratings correlated with the global rating of adoption outcome, as depicted in Table [1]." (page 109)。6

\section{Table 1}

Appropriateness for the Child of the Adoptive Placement by Global Rating on Adoption Outcome

\begin{tabular}{|c|c|c|c|c|c|}
\hline $\begin{array}{c}\text { Rating on } \\
\text { Appropriateness }\end{array}$ & Low & Fair & $\begin{array}{l}\text { Global Rating } \\
\text { Good }\end{array}$ & Superior & Total \\
\hline Very inappropriate & - & 4 & 4 & 1 & 9 \\
\hline Inappropriate & 5 & 6 & 8 & 2 & 21 \\
\hline Appropriate & 11 & 35 & 41 & 13 & 100 \\
\hline Very appropriate & 7 & 24 & 59 & 23 & 113 \\
\hline No information & - & 3 & 4 & $=$ & 7 \\
\hline Total & 23 & 72 & 116 & 39 & 250 \\
\hline
\end{tabular}

In addition, each placement was correlated with a "preference image" index for the adoptive parents. "In a sense, this was a composite rating of 
parental preferences in conjunction with the degree to which the child met these preferences." 7 (p. 108.) Table 2 shows how the preference image ratings related to the global ratings of the adoption outcomes.

\section{Table 2}

Degree to Which Child Met Parents' Preference Image, by Global Rating on Adoption Outcome

\begin{tabular}{lccccr}
\hline $\begin{array}{c}\text { Preference Image } \\
\text { Rating }\end{array}$ & Low & Fair & $\begin{array}{c}\text { Global Rating } \\
\text { Good }\end{array}$ & Superior & Total \\
\hline $\begin{array}{l}\text { Not close to image } \\
\begin{array}{l}\text { Some resemblance to } \\
\text { image }\end{array}\end{array}$ & 1 & 5 & 1 & 1 & 8 \\
$\begin{array}{l}\text { Close but lacks im- } \\
\text { portant factor }\end{array}$ & 7 & 13 & 25 & 3 & 21 \\
$\begin{array}{l}\text { Almost complete } \\
\text { agreement }\end{array}$ & 11 & 42 & 80 & 8 & 53 \\
No information & 2 & 2 & 4 & 27 & 160 \\
Total & 23 & 72 & 116 & 39 & 850 \\
\hline
\end{tabular}

At first glance it looks as if pre-adoption ratings of appropriateness are more highly correlated with adoption outcome than are the ratings of the closeness of the match between the child and the adopting parents' preferences; there are more observations on the diagonal and fewer on the off-diagonal corners of Table 1 than Table 2. In fact, the chi-squared test for independence between the rows and columns yields values of 15.7 for Table 1 and 15.1 for Table 2, confirming this impression. Interestingly, however, the critical value for this test with 9 d.f. is 16.9 , meaning that at the $5 \%$ level of statistical significance the hypotheses cannot be rejected that the rows and columns are independent of each other in both tables. These 
tests suggest that careful home studies by social workers to judge the appropriateness of an adoption do not do much better than the parent $s^{\prime}$ preferences at predicting the outcome of the adoption; and neither can do a significantly better job than if they weren't done, and the children were allocated to adoptive homes on a purely random basis.

But perhaps these are the wrong tests. Perhaps the goal of society is to avoid social costs imposed by adoptions that don't work out. It may be that everyone would be happier with social policy toward adoptions if egregious errors were avoided, but no one really cares much whether an adoption has a global rating of good or superior. Perhaps, to reflect this satisficing goal, a better test would be to decide which adoptions were ok and which ones weren't. This task is easy when one refers to the descriptions of the categories:

Rating 4: Superior

These families exhibited outstanding joie de vivre and enthusiasm. They displayed skillful childrearing practices, and acknowledged and confronted problems of life. The children were thriving. The parents were enthusiastic about adoption, highly compatible, and cooperated to give the children a warm and encouraging atmosphere. They provided good models for the children's emotional maturation. The children were happy, responsive, and related well to each other and to others. If a child had suffered from physical or emotional disability prior to being adopted, marked improvement had taken place. The child's performance was consistent with his assumed potential. The family as a unit showed a pronounced ability to face problems squarely, evaluate them realistically, and resort to mature methods of solving them.

\section{Rating 3: Good}

Each of these units had healthy familial relationships and showed strong affection. The children were developing well. Some parenting functions may have been awkwardly performed. The parents were compatible and both were involved in nurturing the children, but not quite as successfully as a rating- 4 family-the parents might be less vivacious, less adept, or there might be some other limiting factor. For example, one parent might find that taking responsibility for the children was a difficult task, but the other parent counterbalanced this with better than average strengths. As in a " 4 " rating, the children were happy and responsive, and related well to others. A child's performance was consistent with his estimated potential. Existing family problems were relatively minor 
and were being dealt with adequately. The family might exhibit weaknesses in coping with some problems, but most problems were being solved in a mature manner. Excessive pressure for achievement was put on a child by some of these families.

Rating 2: Fair

In these cases, the parents were deficient in their capacity to deal with problems regardless of whether these originated with the child, the home setup, or within the parents themselves. There were, however, some basic strengths. Some of these parents had problems in the marital relationship and transferred them to the parent-child relationship. In families with children of both sexes, sex-linked conflicts and neurotic entanglements were sometimes seen (e.g., mother-son clashes). Parental models for the children were inadequate. Quite frequently the fathers were detached from the center of family relationships, because they either were $a b$ sorbed in outside interests or had been shoved out of these relationships

by the mother Some of the parents were of limited emotional or intellectual capacity. In other cases the child might have brought problems with him that were unusually taxing and beyond the parents' capacity to manage. The children were often found to be anxious or immature, troubled or disturbed. The child's early symptoms of emotional trauma were unimproved or only slightly better, and his school performance or social adjustment was below expectation. The parents of children under 10 might not have reported such symptoms, but the distorted family relationships gave clear evidence that healthy personality development was not taking place.

Rating 1: Low

In these families, there was pathology in the parent-child relationship that affected the child's growth and proper development. Emotional damage to the child was visible. Either separately or together, the parents, however well intentioned, could not give the children the nurturing required. As with a " 2 " rating, the children appeared anxious, immature, or disturbed. The child's performance and social development were below expectation. Unmistakable evidence was present of emotional distress. The family faced serious problems which it was unable to handle and which threatened to impede the child's progress toward healthy adulthood. In some cases, some of these problems may have been caused because the child's original handicaps at placement were irreparable. 
Aside from the question of how any worldly adoption could qualify for the superior rating, the categories quite clearly indicate that those adoptions judged good and superior had characteristics which would generally be desired in society and those rated fair and low had characteristics which society would probably like to try to avoid in future adoptions. Further, this two-way classificatory scheme seems more appropriate than a more elaborate one since the decision to be made is (at least in each case observed in isolation) a simple two-way decision of whether or not an adopting family should receive parenthood rights to a particular child. Tables 3 and 4 show the regrouping of the data to conform with these two-way classifications.

\section{$\underline{\text { Table } 3}$}

Agency Match

\begin{tabular}{|c|c|c|}
\hline $\begin{array}{c}\text { Predicted } \\
\text { Out come }\end{array}$ & \multicolumn{2}{|c|}{ Outcome } \\
\cline { 2 - 3 } not ok & ok \\
\hline ok & 15 & 15 \\
\hline
\end{tabular}

chi-squared $=2.16$

\section{Table 4}

Image Match

\begin{tabular}{|c|c|c|}
\hline \multirow{2}{*}{$\begin{array}{c}\text { Predicted } \\
\text { Outcome }\end{array}$} & \multicolumn{2}{|c|}{ Outcome } \\
\cline { 2 - 3 } not ok & 18 & ok \\
\hline ok & 73 & 140 \\
\hline
\end{tabular}

$$
\text { chi-squared }=8.49
$$


Under this more useful classificatory scheme, the results are reversed: simple image match appears to be a better predictor of adoption outcome than the hours of interviewing and matching by social workers. Furthermore, the $5 \%$ critical value of $\chi^{2}$ for a test of independence of the rows and columns of Tables 3 and 4 is 3.84 , indicating that image match can significantly predict the outcome of an adoption, whereas adoption agencies cannot.

Image matching is probably a very good proxy for how well a market would work in the allocation of parenthood rights. It is unlikely that people would purchase the entitlement to any good or service which did not match their pre-purchase images unless they were deceived. Consequently, assuming that the market would do as well as image matching in Tables 3 and 4 it can be seen that the alleged social savings of using adoption agencies do not exist and are probably negative. A market would allocate parenthood rights in such a fashion that there would be lower social costs not only in the form of reduced negative externalities but also in the form of reduced administrative costs.

\section{Qualifications and Lamentations}

The data presented in Section II must be used cautiously. The fact is that all of the homes studied had been screened by adoption agencies prior to the placement of a child in them. There may have been some parents who would have liked to acquire parenthood entitlements but who were eliminated from the sample because agency workers decided that the probability would be unduly high that those parents would raise children in such a fashion that 
substantial social costs would be generated. There is some different evidence available, however, which suggests that even the screening activity of adoption agencies yields small, if any, benefits.

There have been numerous studies carried out of the outcomes of independent adoptions, i.e., adoptions not involving an agency, but generally involving an intermediary such as a doctor, lawyer, or nurse. 8 Typically, these studies have found that independent adoptions have a lower success rate than agency placements. Yet often times the samples are not directly comparable. Once corrections in the data are made to allow for the problems of older children, for the lack of counselling, and for independent placements of children with friends or relatives, then generally independent adoptions generally cannot be shown to have a lower success rate than agency adoptions. As noted above, another function of adoption agencies includes the provision of pre- and post-adoption counselling. While it has commonly been assumed that the benefits of this counselling are positive (and this assumption may be open to question), little if any work has been done on the net social benefits of this counselling. If the screening and matching benefits of having adoption agencies are negligible, then the only remaining justification for their operation must be that their counselling benefits outweigh their entire costs. There is no evidence available at present on these costs and benefits.

One of the possible benefits of allowing parenthood markets to develop is the reduction or elimination of administration costs of operating adoption agencies. Caution must be used in this assertion, however, because many of the costs experienced under the present agency scheme would also be 
experienced under a market regime. These might include pre- and post-natal care of the biological mother, decision-making time for the prospective parents, and some of the post-natal care for the child. Despite our strongest wishes (often incorporated into implicit assumptions), markets do not work costlessiy. Information and decision costs exist, along with the negotiation and contractual costs.

Even though there are qualifications, the case for the use of the market to allocate parenthood rights is very strong. Why then has not such a market been legitimized? As a matter of fact, it is becoming increasingly legitimized through independent (grey market) adoptions which include side payments for the intermediaries which are often legal yet considerably larger than one might expect when one considers the costs of the intermediary service. Biological mothers are sometimes provided with luxurious environments as well as educational allowances by adopting parents. ${ }^{9}$ Furthermore, contractual relationships appear to have been legitimized between parents and women who are willing to carry and give birth to a child created by the sperm and egg of the parents. 10

But these examples are only partial legitimizations of the market for parenthood entitlements. There is still apparently some strong resistance to the full legalization of the market. There are, perhaps, three major reasons for this resistance. First, some people object to the selling of human beings; visions of depraved slavemasters are easily conjured up. It may be purely a matter of semantics, but it should be noted that throughout this paper no reference has been made to the market for children. What has been discussed has been the transfer of parenthood rights. No parent owns 
a child; a parent only has rights to the parenthood of a child. And this entitlement is clearly limited by such custom and legislation as education, child labour, and child abuse laws.

Second, many people apparently object to the practice of paying mutually consenting adults to engage in fornication (are there any jurisdictions in North America where prostitution is legalized?). Paying biological parents for the parenthood rights to their offspring is viewed as roundabout prostitution and, hence, to be proscribed by policy.

Third, concern has been raised about the erosion and eventual nonexistence of a market for parenthood rights to offspring who currently fall into the category of "hard-to-place". A market could deal with these situations in one of several ways. The question to be answered is, "who will bear the risk of bearing a child in whom no one values parenthood rights?" If the biological parents are obliged to bear the risk (i.e. they cannot donate their parenthood rights to the state), one would expect an active insurance type of market to develop. Similarly, if intermediaries were required to bear the risk, one would also expect an insurance market to evolve. All that is important, for social policy and economic efficiency, is that the burden of bearing such a risk be clearly specified so that the contracting parties can negotiate about the possible reassignment of the risk: Clearly, whoever ultimately bears the risk, secondary markets with negative prices will evolve for parenthood rights (or more limited rights and obligations) to such children. The state need not become involved, nor need the taxpayers become ultimate bearers of this risk. 
Despite the fact that most arguments against allowing or encouraging a market in parenthood entitlements to evolve can be effectively countered, one can easily suspect that the markets will not be allowed to develop in the foreseeable future. Nevertheless, our lamentations should not be too loud or too long; when social benefits outweigh social costs, and when private benefits outweigh private costs, experience has been that markets slowly evolve by chipping away at social inhibitions. New institutions are created and the next best thing to markets will emerge as the laws are gradually changed and reinterpreted. 


\section{Footnotes}

${ }^{1}$ Posner and Landes, "The Economics of the Baby Shortage," J, of Legal Studies ; "Experiment in Independent Adoptions," Social Casework, 1977; "Cost/Benefit Analysis in the Social Services: The Example of Adoption Reimbursement," Soc. Serv, Rev, 1977; D. W. Young, "Referral and Placement in Child Care: NY City Purchase of Service System," Public Policy 22, No. 3, summer 1974 at 293-327; Meezan, Katz, and Russo, Adoptions Without Agencies: A Study of Independent Adoptions; Child Weflare League of America Inc. (1978), "Subsidized Adoption Programs," J1. of Family Law, VoI. 15 (1976-7 at 750); Witmer, Herzog, Weinstein and Sullivan, Independent Adoptions: a Followup Study (1963); Russell Sage Foundation, "Independent Adoptions: Is the Black and White Beginning to Appear in the Controversy Over Grey Market Adoptions?" Duquesne L. Rev, 18: 629-52, Spring 1980; M. Krones, "Stimulation of Independent Adoptions - a Sensible Approach to Eradicating the Baby Black Market," Orange County B.J. 6: 192-204, Summer 1979; "Black Market Adoptions," Catholic Lawyer 22: 48-69, Winter 1976; "Matching for Adoption: A Study of Current Trends," Catholic Lawyer 22: 70-86, winter 1976; Louise Raymond, Adoption and After, Harper and Row (1974).

2 The adoptions which take place independently of adoption agencies are often referred to as "grey market" adoptions because, while they are not illegal in most jurisdictions, they sometimes include substantial facilitation payments to intermediaries.

${ }^{3}$ See Meezan, et al, supra n. 1; "I Could Place 500 Babies," Toronto Star, April 15, 1978; "Baby Selling Scheme Linked to BC," Vancouver Sun, May 3, 1980; "Media Reports of Baby Sales Denied," Winnipeg Free Press, March 23, 1981; plus articles in the New York Times (April 13 and 27, 1980).

4. DeTray, "Child Quality and the Demand for Children," and "Comment" by 0. Ashenfelter, J,P.E, Mar./Apr. 1973.

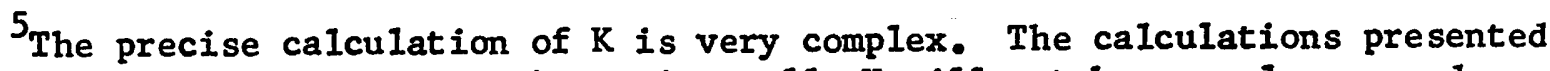
in the text indicate that even when $n$ is small, $K$ will not be very large, and the amount of double counting will not be large relative to the entire lost consumer surplus.

6. A. Lawder, K. D. Lower, R. G. Andrews, E. A. Sherman, and J. G. Hill, A Followup Study of Adoptions: Post-Placement Functioning of Adoption Families, Child Welfare League of America, Inc. (1969).

Ibid. 
${ }^{8}$ See Witmer et al and, in particular, Meezan et al who state (p. 42):

Despite the reports of risks in independent adoptions and the occurrence of "legally questionable activities," the agencies considered a remarkably high proportion of independent homes as good or better than homes where the children are placed through an agency. Almost half of the agencies reported that nearly all independent homes are as good or better in providing physical care for the child, and more than one-third consider almost all the homes as good or better in providing emotional care. Only $15 \%$ of the agencies regarded no more than half of the homes as good as agency homes in providing physical care and one-third reported that half or fewer of the homes are as good or better in providing emotional care.

\section{Ibid.}

10"U.S. is Caught Unprepared for Surrogate Motherhood," Toronto Globe and Mail, July 15, 1981 . 